\title{
Registered nurse-performed flexible sigmoidoscopy in Ontario: Development and implementation of the curriculum and program
}

\author{
Mary Anne Cooper MSc MD MEd FRCPC ${ }^{1,2,3}$, \\ Jill Margaret Tinmouth MD PhD FRCPC ${ }^{2,3,4}$, Linda Rabeneck MD MPH FRCPC 3,5
}

\begin{abstract}
MA Cooper, JM Tinmouth, L Rabeneck. Registered nurseperformed flexible sigmoidoscopy in Ontario: Development and implementation of the curriculum and program. Can J Gastroenterol Hepatol 2014;28(1):13-18.
\end{abstract}

Although colorectal cancer is a leading cause of death in Canada, it is curable if detected in the early stages. Flexible sigmoidoscopy has been shown to reduce the incidence and mortality of colorectal cancer in patients who are at average risk for this disease and, therefore, is an appropriate screening intervention. Moreover, it may be performed by nonphysicians. A program to enable registered nurses to perform flexible sigmoidoscopy to increase colorectal cancer screening capacity in Ontario was developed. This program incorporated practical elements learned from other jurisdictions as well as specific regional considerations to fit within the health care system of Ontario. The nurses received structured didactic and simulation training before performing sigmoidoscopies on patients under physician supervision. After training, nurses were evaluated by two assessors for their ability to perform complete sigmoidoscopies safely and independently. To date, 17 nurses have achieved independence in performing flexible sigmoidoscopy at 14 sites. In total, nurses have screened $>7000$ Ontarians, with a cancer detection rate of 5.1 per 1000 screened, which is comparable with rates in other jurisdictions and with sigmoidoscopy performed by gastroenterologists, surgeons and other trained nonphysicians. We have shown, therefore, that with proper training and program structure, registered nurses are able to perform flexible sigmoidoscopy in a safe and thorough manner resulting in a significant increase in access to colorectal cancer screening.

Key Words: Colorectal cancer screening; Flexible sigmoidoscopy; Registered nurses

Oolorectal cancer (CRC) is the second leading cause of cancer deaths in Canada. It is estimated that approximately 8700 individuals in Ontario were diagnosed with CRC in 2013 and that 3350 died from the disease (1). If detected sufficiently early, however, $>90 \%$ of CRCs can be cured.

Several screening modalities for CRC exist, enabling early detection or even prevention. Importantly, it has been shown that flexible sigmoidoscopy (FS), a procedure associated with minimal risk, cost and patient inconvenience, is one such intervention that can reduce the risk of CRC (2,3). Compared with colonoscopy, FS requires less onerous preparation and has a lower procedural risk. It is also typically performed without sedation so that the time required for FS is much less than that for a colonoscopy (4). As such, FS is considered to be an appropriate screening method for CRC in several jurisdictions including Canada. The Canadian Association of Gastroenterology position statement cites FS as a viable option for screening persons who are at average risk for CRC (5).

\section{Les infirmières autorisées effectuant des sigmoïdoscopies flexibles en Ontario : l'élaboration et la mise en œuvre du cursus et du programme}

\begin{abstract}
Même si le cancer colorectal est une cause majeure de cancer au Canada, on peut le guérir s'il est décelé au stade précoce. Il est démontré que la sigmoïdoscopie flexible réduit l'incidence de cancer colorectal et la mortalité y étant associée chez les patients qui courent un risque moyen de cette maladie et, par conséquent, qu'elle constitue une intervention de dépistage pertinente. De plus, elle peut être effectuée par des nonmédecins. Un programme visant à faire exécuter des sigmoïdoscopies flexibles par des infirmières autorisées afin d'accroître la capacité de dépistage du cancer colorectal a été élaboré en Ontario. Ce programme incluait des éléments pratiques tirés d'autres territoires de compétence et tenant compte de considérations régionales précises pour fonctionner dans le système de santé de l'Ontario. Les infirmières recevaient une formation didactique et en simulation structurée avant d'effectuer des sigmoïdoscopies sur des patients sous la supervision d'un médecin. Après la formation, les infirmières étaient notées par deux évaluateurs pour leur capacité d'exécuter des sigmoïdoscopies complètes seules et de manière autonome. Jusqu'à présent, 17 infirmières se sont mises à faire des sigmoïdoscopies flexibles en toute autonomie dans 14 établissements. Au total, les infirmières ont fait le test de dépistage auprès de plus de 7000 Ontariens et obtenu un taux de dépistage du cancer de 5,1 cas sur 1000 personnes faisant l'objet du test, ces taux étant comparables à ceux d'autres territoires de compétence et aux sigmoïdoscopies exécutées par des gastroentérologues, des chirurgiens et d'autres non-médecins formés. Nous avons donc démontré qu'en possédant une formation et une structure de programme convenables, les infirmières autorisées sont en mesure d'effectuer des sigmoïdoscopies flexibles de manière sécuritaire et détaillée, ce qui entraîne une augmentation importante de l'accès au dépistage du cancer colorectal.
\end{abstract}

Additionally, it has been shown that nonphysicians can perform FS, which allows flexibility in the distribution of the procedure to maximize patient access. In particular, registered nurses (RNs) have been shown to be able to perform FS as proficiently as physicians in terms of depths of insertion of the endoscope and in polyp detection rates (6).

It is imperative that there is access to effective screening to benefit from the impact such interventions can offer to reduce the morbidity and mortality of CRC. To provide adequate CRC screening capacity in Ontario, we developed a program to train RNs to perform FS. To achieve this, several hurdles had to be overcome, requiring the coordination of multiple organizations. Issues included ensuring malpractice insurance coverage for both nurses and physician trainers, developing institution-specific medical directives, developing physician remuneration packages, developing participant recruitment plans for each centre involved, and creating and delivering an appropriate curriculum and evaluation process. Support was obtained from the Registered Nurses Association of Ontario, the Ontario Nursing

${ }^{1}$ RNFS Program, Cancer Care Ontario; ${ }^{2}$ Department of Gastroenterology, Sunnybrook Health Sciences Centre; ${ }^{3}$ Department of Medicine, University of

Toronto; ${ }^{4}$ ColonCancerCheck Program, Cancer Care Ontario; ${ }^{5}$ Cancer Care Ontario and the University of Toronto, Toronto, Ontario

Correspondence: Dr Mary Anne Cooper, Department of Medicine, Sunnybrook Health Sciences Centre, 2075 Bayview Avenue,

Room HG64, Toronto, Ontario M4N 3M5. Telephone 416-480-6799, e-mail maryanne.cooper@sunnybrook.ca

Received for publication August 16, 2013. Accepted September 16, 2013 
Secretariat, the College of Physicians and Surgeons of Ontario, the Canadian Medical Protective Agency, the Michener Institute of Applied Health Sciences, Cancer Care Ontario (CCO), and the Ministry of Health and Long-term Care. Much of the groundwork and the solutions to the hurdles we encountered have been reported elsewhere (7).

The objective of the present report is to describe the training and education component of the Ontario Registered Nurse-performed Flexible Sigmoidoscopy (RNFS) initiative, outlining the curriculum and the pedagogical principles used in training the nurses and certifying them for independent practice.

\section{METHODS}

The first formal RNFS training program began in Ontario in 2005, after a year of planning and research of similar programs in other jurisdictions. Since then, there have been four additional training programs conducted as part of this CRC screening initiative. The Ontario program has evolved with each iteration as lessons learned became incorporated. This section describes considerations made and research performed as preparatory work in advance of the first implementation of the training program and the subsequent refinements incorporated over time. These factors included research and site visits to other jurisdictions, investigation into the legal parameters in which medical professionals work in Ontario and consideration of the large geographical area that constitutes this province.

Lessons from other jurisdictions - Kaiser Permanente, California, USA It was acknowledged at the outset that other jurisdictions had successfully developed nurse FS programs to screen patients for CRC. Most notably, Kaiser Permanente in California (USA) had developed a program in the early 1990s to help them achieve acceptable screening rates for the patient population within their health maintenance organization (HMO). Their nurse-performed FS program was fundamental in achieving a screening participation rate of $80 \%$ of eligible $\mathrm{HMO}$ members (8). The lead educator (MAC) of the Ontario RNFS program received an education travel grant from the Professional Association of Internes and Residents of Ontario to visit three Kaiser Permanente sites in 2004 to assess their program for its applicability in Ontario.

Significant lessons learned during these visits included the observation that a model of a strong physician-nurse dyad was critical for essential mentorship to occur so that the nurse always felt supported and able to approach his/her physician mentor with all questions. It was also necessary for the trust to be reflected back to the physician who needed to be comfortable in transferring patient care to the nurse.

By extension, the Kaiser Permanente program had observed that the nurses who performed best had at least two years of experience as endoscopy assistants before commencing training in performing FS. By this point in their careers, the nurses had determined whether they enjoyed gastrointestinal endoscopy and, therefore, were likely to remain in this field for a reasonable length of time. This improved the return-oninvestment made in training, increased the likelihood that the nurses were truly content in this vocation and that the pool of trained nurses could be maintained, both for the sustained functioning of the program and for nursing collegiality. Importantly, the physicians already had a foundation of trust with the nurses who trained in FS.

It was also noted that all of the nurses interviewed in the Kaiser Permanente program emphasized several key elements in their practice. They believed that there was significant professional benefit in having nurse coworkers who were engaged in the program work with them so that they did not perform FS without the support of their colleagues. This was particularly noted among the nurses who had been with the program when it began and when they were changing their practice profile from endoscopy assistants to endoscopists.

All of the nurses interviewed during the site visits to California and who performed FS also commented on the significant role change from supporter to service provider that performing FS had brought to their careers. This specifically included the notion that they had been accustomed to comforting patients who experienced discomfort during the procedure and had become the ones who caused patient discomfort as they performed the procedures. They emphasized the need for support with this professional practice change.

\section{Lessons from other jurisdictions - National Health Service, United Kingdom}

It was recognized that there was also the need to provide standardization among the physician leads at each site who would train the nurses to perform FS. Some centres had experience in training endoscopy learners if they were associated with resident physician training. Not all centres, however, had such experience and, therefore, there was a need to be sure all physician trainers were aware of approaches to teaching endoscopy, the related pedagogy and the particular issues related to the scope of practice of the $\mathrm{RN}$ endoscopists in Ontario. The education lead (MAC) received financial support from CCO to travel to the United Kingdom to participate in their well-developed 'Trainthe Endoscopic-Trainer' program to learn the pedagogical principles involved in teaching endoscopy trainers.

In addition to the practical element of training, it was observed that physician leads and physician trainers required an orientation to the role of the $\mathrm{RN}$ as an endoscopist and the scope of practice they could follow within the parameters of the Public Hospitals Act of Ontario (9). With these considerations in mind, a 'Train-the-Trainer' element and RNFS program orientation for physicians was incorporated into the Ontario RNFS training program in 2007.

\section{Ontario requirements}

Successful implementation of our RNFS program required that the nurses be able to perform FS and to decide appropriate follow-up based on the results of the procedure. This required that a nurse assume some autonomy in interpreting the results of the sigmoidoscopy. It was the responsibility of the nurse to follow-up results of any tissue samples taken during the FS, review with the physician trainer and ensure appropriate actions were pursued. The nurses, therefore, had to be educated on the pertinent physiology and pathophysiology of polyps and CRC, and be able to communicate this information appropriately to their patients. This communication of information had to occur within the bounds of the Public Hospitals Act of Ontario that precludes nurses from giving diagnoses (9). The nurse endoscopists, therefore, were educated on how to relay this information appropriately. For example, nurses could not give a diagnosis of 'diverticulosis' and, therefore, were required to present findings to patients as 'You appear to have diverticulosis'.

The nurses were also an important link in communicating the results of the FS, not only to their supervising physician, but also to the patients' primary care physicians. They ensured that appropriate correspondence about the procedure and any subsequent results were transmitted to the primary care physicians according to site-specific protocols.

Once trained, nurses worked with some independence, although the formal assignation of a physician mentor still applied. The efficiency of the functioning of this dyad reflected the trust that needed to exist between the nurse and the physician and underpinned the success of the program.

Finally, the Ontario program had to be designed such that not only did the curriculum cover the necessary didactic material and practical training but that it could be implemented over the large geographical area of Ontario (1,076,00 $\mathrm{km}^{2}$ [larger than France and Spain combined]) (10).

After considering the work performed at Kaiser Permanente and the training expertise from the United Kingdom, and considering the specific geographical challenges faced in Ontario, a curriculum was developed that would bring the nurses together for basic training but obtain their experiences in performing FS on patients at their home hospitals. The following section describes how this program has manifested in Ontario. 


\section{RESULTS}

\section{The training program}

Given the background research performed and the particular needs of Ontario, a program was developed that included the following elements:

1. Pretraining observation at the nurses' home hospital sites;

2. Didactic curriculum and simulator training course at a central training site;

3. Train-the-endoscopic trainer for physicians at a central training site;

4. Clinical experience at the home hospital site with physician trainers; and

5. Home hospital site evaluation.

A detailed syllabus was prepared to encompass all elements of the training program. It included space for journaling, tables to record progress on simulators (see below), all of the required didactic material and a $\log$ for on-site training. It was provided to the nurses several weeks before attending the central course so that they could familiarize themselves with the entire course curriculum.

Pretraining observations at the nurses' home hospital sites: One of the first principles considered in the training was that the RNs would assume a role that traditionally had been in the domain of the physician. This role change required that nurses accept both the change in the physical requirements of the task and the philosophical change from supporter to provider. One of the ways in which this challenge was met in the program was to require that the nurses undergo a formal pretraining process of observing a physician perform FS. The purpose of this was to provide the specific opportunity for them to view the difference in the technical aspects of the procedure between the one performing the FS compared with the traditional perspective of the RN assisting. The nurses were also instructed to observe and comment on the role difference from the individual who may cause discomfort during the performance of the procedure compared with one who comforts the patient. They had the opportunity during this period of observation to discuss with the physician technical aspects of the procedure they neither had observed nor with which they previously had had concerns as an assistant.

Didactic curriculum and simulator training at a central training site: The next phase in training was to teach the nurses the theoretical and practical basics of performing FS. The nurses were brought together from around the province to Toronto (Ontario) for one week. The program was conducted at the Michener Institute for Applied Health Sciences in a setting that allowed classroom and practical training. The classroom curriculum included discussions on basic anatomy, physiology and pathophysiology as they applied to the performance of flexible sigmoidoscopy, the polyp-to-cancer sequence, and role of FS in cancer prevention and early detection. Other material covered during this week included a discussion of the nurses' practice limitations, how to obtain consent, and how to dictate and/or report the procedures.

Throughout the one-week course, the nurses participated in a professional practice assessment led by a nursing faculty member. This involved journaling, a review of nursing principles, a dialogue regarding the medical directives and a discussion of their evolving role. It included a reflection of their observations made before the course and of those made during the week.

The nurses began their practical training on the first day of the week with an orientation to a real endoscope to learn about its various functions. The nurses were then introduced to the simulators. Considerable time was scheduled for the nurses to practice on the simulators during the week. Two instructors circulated among the learners to provide instruction and feedback but the nurses also had ample time for independent practice.

The nurses were introduced to the practical aspects of performing FS using two types of simulators. A box simulator was available for basic training to allow the nurses to develop facility with the endoscopes, which was built for this course (11) based on a previously developed 'choose-the-hole' fibre-optic intubation simulator (12). It consisted of an open box with a series of panels in which numbered holes were drilled and through which an endoscope could be passed. A list was developed that outlined the appropriate series of numbered holes through which the nurse would direct the endoscope. The series of numbers were listed in order of difficulty to guide training.

The training course also used a high-fidelity simulator (EndoVR endoscopy simulator, CAE Healthcare, Canada) to provide a sense of realism and haptic feedback (13). Programmed cases were also presented to the nurses in terms of increasing difficulty to guide their training.

For all of the skills of the course to coalesce, a session with standardized patients was held in the latter half of the week. For this encounter, a standardized patient was interviewed by the trainee to obtain a focused history and consent for the procedure. The standardized patient then lay on a stretcher in the left decubitus position in close proximity to the simulator. The sounds of the simulator were transmitted to the standardized patient by an earphone and the standardized patient then vocalized the sounds as cued by the simulator so that the nurse would have to respond to the patient while performing the procedure. On completion of this simulated FS, the nurse was required to dictate a report of the procedure. The report was transcribed and reviewed to provide feedback to the nurses.

Train-the-endoscopic trainer for physicians at a central training site: On completion of the one-week course, the nurses returned to their home hospital sites to commence practical training under the supervision of physicians with experience in endoscopy, typically gastroenterologists and general surgeons. To provide consistency in performance across the province and to expose the site trainers to the concepts of teaching endoscopy if they came from sites not affiliated with a university teaching program that already trained resident doctors, a lead physician from each site attended the course in Toronto for a day of training that overlapped with the nurses at the end of their week-long course. A representative of CCO met with the physicians to review administrative details and discuss the provincial screening plan. The physicians were oriented to the program, including the limits of the nurses' scope of practice, and reviewed basic pedagogical principles of teaching endoscopy. The physicians then had an opportunity to explore these principles and practice teaching endoscopy in training exercises with the nurses in the course. In addition to providing the physicians with essential information and creating a provincial standard in the expected performance of the RN endoscopists, the interactive session with nurses was an excellent interprofessional experience.

Coordination of the one-week course elements was critical in accomplishing all the training goals. Figure 1 represents a typical schedule for a course within the program.

Clinical experience at the home hospital site with physician trainers: After returning to their home hospital sites from the central training course, the nurses performed FS on real patients enrolled into the program for screening, which included patients 50 to 75 years of age who had no symptoms and who did not have a family history of CRC. To help ease their transition into performing procedures on patients, the nurses first completed 25 procedures by simply withdrawing the endoscope under supervision. Following this, they then performed 50 full procedures, still under supervision of the physician trainer. The nurses were required to perform these procedures before being considered for evaluation. If, in the opinion of the nurse and the trainer, more experience was needed, the nurse continued to perform more procedures under supervision until prepared.

Home hospital site evaluations: Once ready for independent practice, two evaluators travelled to the nurse's site to assess her/him. It was decided a priori that each nurse would perform five flexible sigmoidoscopies on which she/he would be evaluated. Each site typically scheduled six patients, however, in case one patient was unable to make the appointment or a bowel preparation was particularly poor. The evaluators used both a checklist and a global rating scale to guide their assessments of the candidates (14). The physician trainer from the home hospital site was required to be in the room for all of the cases because the assessors were visitors to the institutions and did not have privileges at any of the sites. The physician trainer was also asked to complete the checklists and global rating scales to assist in the evaluation of the nurse. 


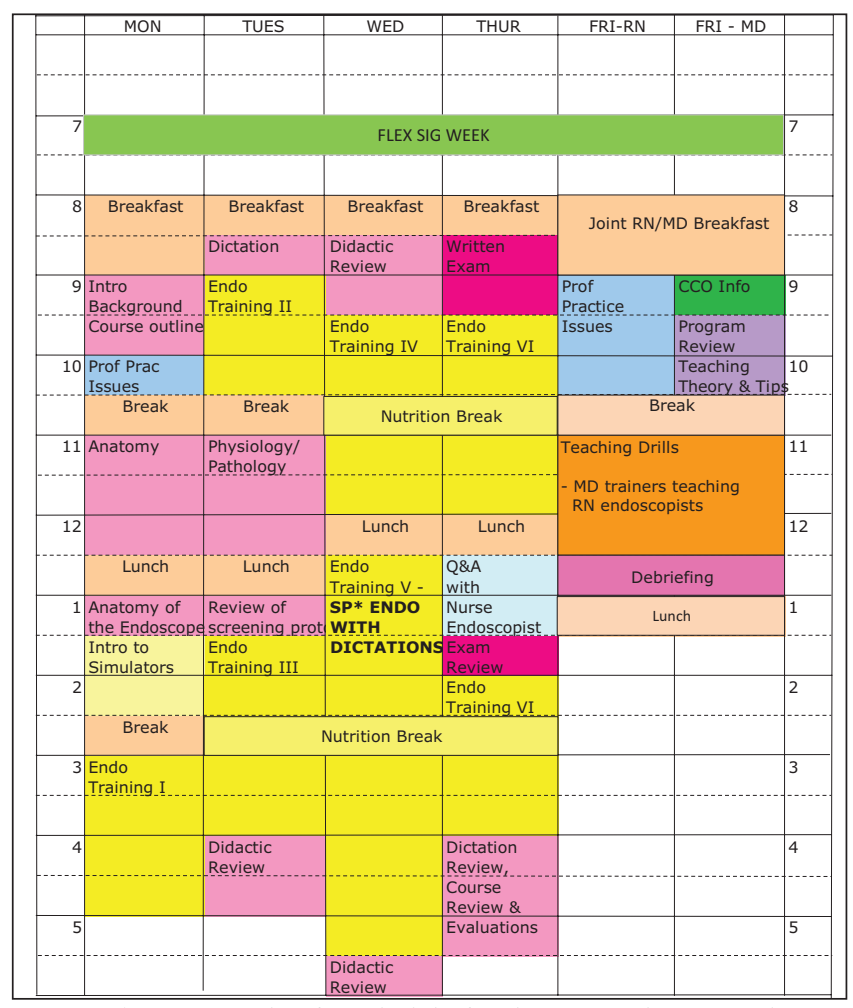

Figure 1) An example of a schedule for the one-week registered nurse $(R N)$-performed flexible sigmoidoscopy training course. CCO CancerCareOntario; Endo Endoscope; MD Medical doctor; Prac Practice; Prof Professional; QEAA Question and answer

\section{Independent practice}

Once approved for independent practice, the nurses were then able to continue performing FS on appropriate patients according to site-specific guidelines and medical directives. A physician trainer was no longer required to be in the endoscopy room while the nurse performed the procedures but one was required to be accessible if the nurse encountered difficulties, either with technical issues in performing the FS or with interpretation of findings. Each facility determined a schedule that would best work for that site. If a physician's outpatient office was located near the endoscopy suite, he/she might see outpatients while the nurses performed FS in the suite. In most instances, however, the nurses were scheduled to perform FS while a physician trainer worked in another room in the endoscopy unit.

\section{Additional considerations \\ In some cases, it took considerable time for nurses to achieve the skills necessary to be evaluated and deemed competent for individual prac- tice. As such, refresher courses were run for the nurses and they came to Toronto for two days of review as deemed necessary by the nurses themselves and the site coordinators. Didactic material that had been covered in the course was reviewed, and the nurses also spent time on both the box and high-fidelity simulators. The nurses were encouraged to bring forward any questions they had about the theoretical material and practice issues after having acquired some practical experience.}

\section{Evaluations by the nurse endoscopists}

The nurses' experience in the one-week central course has been critical to the success of the overall training because it provided the foundation for the theoretical knowledge and practical skills, and firmly established a rapport among the nurses and their physician trainers who returned to work at sites broadly distributed throughout the province. These courses and the nurses' involvement in the program as a whole have been evaluated and met with a high level of satisfaction by the nurses. They have felt valued in that they have been able to expand their scope of practice, lead in a new initiative for nurses and participate more directly in CRC screening in Ontario.

Typical comments from anonymized evaluations of the courses included the following:

- The course was above my expectations. Fantastic support and encouragement by teachers and colleagues.

- The course was amazing. [I] learned so much.

- Got great basic skills to build on.

- Use of the simulators [was] excellent.

- For one week the knowledge and skill that was obtained was excellent. I felt confident leaving here. I know I still have lots of skill and knowledge to gain but look forward to the challenge and look forward to the future.

- It was a wonderful week. Everyone was very friendly; went out of their way to make us feel comfortable!!! Thoroughly enjoyed would recommend the program to others.

\section{Program results and impact}

To date, 17 RNs have achieved independence in performing FS at 14 sites. An additional nine nurses at existing and new sites remain to be evaluated. In total, RNs performing FS, either under supervision or independently, have screened $>7000$ Ontarians. Data from the first 5000 cases have shown a cancer detection rate of 5.1 per 1000 screened.

\section{DISCUSSION}

We described the development of a comprehensive training program to prepare RNs to perform FS in an independent clinical setting, as has been accomplished in other jurisdictions. Nurses have been performing FS in California within the Kaiser Permanente HMO for approximately 20 years. The nurses in the United Kingdom perform both sigmoidoscopy and colonoscopy. As well, an independent clinician in Ontario had reported previously on nurse-performed FS in a single-centre community (15).

\section{Nursing considerations}

To date, five iterations of the training program of the RNFS curriculum have been conducted and many practical aspects have been learned in each implementation. In the first iteration of the program, two large Toronto teaching hospitals were chosen as the sites. Because of resource issues related to maintenance of provision of existing endoscopy services, endoscopy nurses were not available to participate in the training. Despite the recommendations from the Kaiser Permanente system that nurses have at least two years endoscopy experience, we attempted to train nurses from a range of backgrounds, but none who had worked in endoscopy. From a pedagogical perspective, it was believed that if nonendoscopy nurses could be trained, then the training principles could be transferred easily to nurses with endoscopy experience. While the nurses were enthusiastic and interested in adding a new dimension to their career, some simply did not enjoy this type of work. This, combined with logistical issues at sites without significant endoscopy resources, prevented this cohort of nurses from gaining practice independence. In subsequent iterations, sites were chosen that had the reserve in human resources to enable endoscopy nurses to participate in the training.

It must also be recognized that the nurses work within union structures. It has been observed that union rules have required nurses in endoscopy to be transferred to other departments outside of endoscopy within an institution. In one specific instance, an RN who was already performing FS independently was transferred to another unit outside of endoscopy to accommodate a nurse with greater union seniority. The RN trained to perform FS, therefore, had to withdraw from the program and could no longer perform procedures. Not only was she unable to contribute to the provincial screening program, her nursing colleague who was also trained to perform FS no longer had her muchvalued support and assistance. Such realities must be considered when choosing which nurses should be trained to promote sustainability of the program as a whole and at individual sites. 
It has also been observed within our program and, as recommended from the Kaiser Permanente program, that it is best if at least two nurses are involved at each site. Because sites are so geographically distant from one another and because there remains the need to consolidate the acceptance of the nurses performing this role in Ontario, there was a significant benefit to a nurse having a local colleague with whom she/he could train and discuss program issues. As the program has matured, we have observed that the implementation at each site worked better with three nurses trained in performing FS. Ongoing program development, therefore, has included a concerted effort to increase the numbers of nurses trained at each site.

To help build camaraderie on a provincial basis, we also learned that regularly scheduled teleconferences with the nurses and the site administrative support staff have been extremely beneficial. The nurses are able to discuss implementation and practice issues to learn additional insights and approaches and the site administrators can confer with others to find solutions to specific concerns such as patient recruitment, site scheduling, medical directives and other practical issues.

\section{Training considerations}

Within the actual training course held centrally in Toronto, practical issues emerged that were addressed to optimize training. It was observed that the nurses were excellent self-directed learners and did well using the simulators independently, with occasional input from the instructors. They diligently worked through the proscribed lists of series on the box simulator and case sequences of the high-fidelity simulator. Once instructions regarding use of the simulators and basic endoscopy principles were given, the instructors would circulate to assist the nurses as needed. The number of simulators, therefore, was a key determinant in the maximum number of learners who could be accommodated during each program. Typically, three box simulators and three high-fidelity simulators were available so that the maximum number of learners was capped at 12 . This allowed nurses to work in pairs at each simulation station and obtain considerable hands-on experience during the one-week training. Having the same equipment but fewer attendees allowed the nurses even more practical training during the week. Such physical arrangements were met with more positive course reviews by the nurses.

The benefits of simulator training have been shown to be of the greatest benefit in learners at early stages (16). We also have observed significant improvements in the nurses' technical ability throughout the one-week training $(14,17)$. Importantly, however, we believe that the simulator also played a significant role in helping the nurses' transition in their professional role from supporter to provider. In particular, the audible and haptic feedback from the high-fidelity simulator and the use of standardized patients to mimic a real environment as much as possible helped the nurses with this transition, having provided them with a sense about the impact of performing this procedure on a patient before their home site clinical training began.

\section{Patient considerations}

It was apparent from the inception of the program that considerable effort and coordination was required to ensure adequate enrollment of patients for RNFS-performed FS. As such, the role of a site coordinator was developed and financed by CCO. The site coordinator's primary role was to contact and inform family physicians and family practice groups in the region of the nurses' home hospital about the program and to encourage patient enrollment for an RN-performed FS as a CRC screening modality in the community.

One of the challenges of this program has been the recruitment of patients to be screened for colonic polyps by RN-performed FS. There were many reasons for this (6) but recruitment has had a significant impact on the training of the nurses because it has hampered their ability to gain experience in a proficient and timely manner, causing delays in the time in which it was expected some nurses would have achieved competence to work independently. Over time, experience showed that a strong network with the community family doctors and the presence of a physician champion at each site were required to establish and maintain momentum in patient recruitment. As noted above, another of the ways this issue was addressed was with the creation of the role of site coordinator to promote the program in local communities. Additionally, it was learned that meeting with the site coordinator's administrative leads for the program for a one-day workshop held in advance of the one-week central course helped in having a recruitment plan in place to which the nurses would return. The regularly scheduled teleconferences with involvement of all sites also helped with recruitment because they shared their specific recruitment challenges and solutions.

\section{Impact of the funding model}

Some of the issues with patient recruitment and site involvement have related to the funding model that was required during the pilot phase of this project. As a project of the Ministry of Health and Long-term Care of Ontario, funding was provided annually through recurrent one-time funding. This hampered the ability of the program organizers to reach out to communities until funding was assured. The consequences of this was that site involvement, selection of nurses to be candidates for training, the running of the actual complete training program (observation, didactic and simulator learning, clinical training and evaluations) and patient recruitment for the specific site all had to be conducted within a period of $\leq 12$ months. The constraints induced by this process contributed to some of the difficulties in patient recruitment. It also led to some short-cuts being taken, specifically, reducing or eliminating the observation component of the training program. We observed, however, that when time allowed for the full observation portion of the program to occur, the nurses were more comfortable when they arrived for the one-week course and had already begun to make the intellectual transition from supporter to provider.

\section{Train-the-endoscopic trainer}

The earliest iterations of training did not directly involve the doctors who would train the nurses. It became apparent that this was a key element of a successful program for several reasons. The nurses must work within the limitations of the Public Hospitals Act of Ontario (9). It was extremely important that the physicians were made explicitly aware of these limitations so that they would know what they could ask of their nurses. The doctors also needed to be informed what the nurses' curriculum contained and the rationale for the inclusions (or exclusion) of material. It was also recognized that while some hospitals were sites for resident training, this was not the case for all. Some element of training-the-endoscopy trainer was deemed essential, therefore, to provide a pedagogical foundation for skills training and consistency across all sites of the province for the nurses in their practical training. There were also administrative issues in the program that were specific to the doctors such as remuneration. Finally, the doctors also needed to know where the RNFS program fit within the provincial screening philosophy. For all of these reasons, it was imperative to incorporate a component in the one-week training course for physician trainers. They were able to obtain the necessary information about the course, learn basic principles of teaching endoscopy and discuss with one another the practical implementation details at their sites. This was incorporated in such a way as to minimize the physician's time required in Toronto and overlap with the nurses. The resultant session has been very successful, particularly the interactive session with the physicians and nurses.

\section{Licenses and hospital privileges}

The design of this program from the outset allowed implementation across many provincial sites without limitations conferred by licenses and hospital privileges by the trainers. The nurses received all of their clinical training involving patients at their sites with physician trainers who held the necessary privileges. The introduction to practical training was conducted on simulators and, therefore, did not require exposure to real patients. When the evaluators travelled to the sites to assess the nurses, the physician trainers at the sites remained present in the room and were able to provide technical intervention when required. 
The fact that the evaluators did not have privileges at any of the distributed sites, therefore, was not of practical concern.

\section{Evaluations}

As the program has grown, a need for more evaluators has emerged. The evaluations are conducted at each site necessitating that the evaluators travel there. Not all nurses at each site attain competence at the same rate and, therefore, to maintain a positive momentum for the site program and the enthusiasm of the nurses, individuals were sometimes evaluated at different times at the same site so that a prepared nurse was not held back if it was believed that the time for her/ his colleague to achieve the same level of competence was going to be excessive. The consequence of this has been that evaluators have needed to make multiple trips to some sites. There have been times, therefore, when the demands on the evaluators' time have been high and they have not been able to get to all sites in a timely manner. It is expected that more evaluators will be trained to conduct these site visits to enable nurses to progress to independence as soon as they are able. This will both reduce the demands on the time of the doctors supervising the nurses who must continue to be supervised directly by the physician trainer until certified for independence, and increase the number of patients being screened.

\section{Project impact}

As discussed above, the RNs have contributed to CRC screening in Ontario by performing FS on $>7000$ individuals. The cancer detection rate of 5.1 per 1000 screened is comparable with rates in other jurisdictions and with FS performed by gastroenterologists, surgeons, nurses, and other trained nonphysicians $(8,18-20)$.

\section{Summary}

The Ontario RNFS initiative has become established at multiple sites across the province. It has been successful in training RNs to perform FS to screen for CRC. The nurses have been able to assume a new professional role while respecting the legal framework in which they must practice. Patient recruitment to this program has been a challenge since its inception. This has been a factor in the training of some

\section{REFERENCES}

1. Canadian Cancer Society's Steering Committee on Cancer Statistics. Canadian Cancer Statistics 2013. Toronto: Canadian Cancer Society; 2013.

2. Atkin WS, Edwards R, Kralj-Hans I, et al. Once-only flexible sigmoidoscopy screening in prevention of colorectal cancer: A multicentre randomised controlled trial. Lancet 2010;375:1624-33.

3. Schoen RE, Pinsky PF, Weissfeld JL, et al. Colorectal-cancer incidence and mortality with screening flexible sigmoidoscopy. N Engl J Med 2012;366:2345-57.

4. Ransohoff DF and Sandler RS. Screening for colorectal cancer. N Engl J Med 2002;346:40-4.

5. Leddin DJ, Enns R, Hilsden R, et al. Canadian Association of Gastroenterology position statement on screening individiuals at average risk for developing colorectal cancer: 2010. Can J Gastroenterol 2010;24:705-14.

6. Ho C, Jacobs P, Sandha G, et al. Non-physicians performing screening flexible sigmoidoscopy: Clinical efficacy and costeffectiveness [Technology report no 60]. Ottawa: Canadian Coordinating Office for Health Technology Asessment, 2006. $<$ www.cadth.ca/media/pdf/277_endoscopist_model_tr_e.pdf > (Accessed April 30, 2013).

7. Dobrow MJ, Cooper MA, Gayman K, et al. Referring patients to nurses: Outcomes and evaluation of a nurse flexible sigmoidoscopy training program for colorectal cancer screening. Can J Gastroenterol 2007;21:301-8.

8. Palitz AM, Selby JV, Grossman S. The Colon Cancer Prevention Program (CoCaP): Rationale, implementation and preliminary results. HMO Pract 1997;11:5-12.

9. Public Hospitals Act R.S.O. 1990, CHAPTER P.40 Consolidation Period: From January 1, 2011 to the e-Laws currency date. Last amendment: 2010, c. 25, s. 27. (Accessed April 30, 2013).

10. About Ontario: Geography <www.ontario.ca/trave-and-recreation/ about-ontario $>$ (Accessed October 25, 2013). nurses who were limited at times by the low numbers of patients. Once this problem was overcome at each site, the nurses have had no difficulty in completing their training. We have been able to create a program distributed throughout the province in a coordinated and organized manner using a structure that has allowed a broad implementation unencumbered by license and hospital privilege issues. A professional network of trained nurses has been created by bringing them together for a core course with relationships maintained by regular tele- and videoconferencing. All of the features of this program make it portable and able to be implemented in most jurisdictions.

\section{CONCLUSION}

Since 2005, the program developed in Ontario to train RNs to perform FS to increase CRC screening has matured. The next step will be to incorporate RNFS into Ontario's organized provincewide CRC screening program. We have shown that, with proper training, RNs are able to perform FS in a safe and thorough manner, resulting in increased access to CRC screening. We continue to expand the program by increasing both the number of sites where the nurses perform screening FS and the number of nurses at each site. Because the structure of the program does not rely on the need for licenses and hospital privileges for the trainers, it has the potential either to be an anchor for a national training program for Canada or to serve as a model that can be implemented in other jurisdictions.

DISCLOSURES: The authors have no financial disclosures or conflicts of interest to declare.

ACKNOWLEDGEMENT: The authors acknowledge Dr Catharine M Walsh MD MEd FRCPC, Division of Gastroenterology, Hepatology and Nutrition, Hospital for Sick Children and The Wilson Centre, University of Toronto, for her contribution in design and inclusion of the box simulator in the program and for her participation in training and evaluation of the nurses.

11. Walsh CM, Cooper MA, Rabeneck L, et al. High versus low fidelity simulation training in gastroenterology: Expertise discrimination. Can J Gastroenterol 2008;22(Suppl A):164A. (Abst)

12. Naik VN, Matsumoto ED, Houston PL, et al. Fiberoptic orotracheal intubation on anesthetize patients: Do manipulation skills learned on a simple model transfer into the operating groom? Anesthesiology 2001;95:343-8.

13. EndoVR <http://caehealthcare.com/eng/surgical-simulators/endovr> (Accessed October 25, 2013)

14. Walsh CM, Cooper MA, Rabeneck L, et al. Flexible Sigmoidoscopy Simulation Training: Task Trainers and Virtual Reality Simulators Both Show Benefit. Research in Medical Education, San Antonio, November 2008.

15. Shapero TF, Alexander PE, Hoover J, et al. Colorectal cancer screening: Video-reviewed flexible sigmoidoscopy by nurse endoscopists - a Canadian community-based perspective. Can J Gastroenterol 2001;15:441-5.

16. Datta V, Mandalia M, Mackay S, Darzi A. The PreOp flexible sigmoidoscopy trainer. Validation and early evaluation of a virtual reality based system. Surg Endosc 2002;16:1459-63.

17. Walsh CM, Cooper MA, Rabeneck L, et al. Task trainers and virtual reality simulators both show benefit in training gastrointestinal endoscopy skills. Association for Medical Education in Europe. Prague, Czechoslovakia, August 2008.

18. UK Flexible Sigmoidoscopy Screening Trial Investigators. Single flexible sigmoidoscopy screeng to prevent colorectal cancer: Baseline findings of a UK multicenter randomized trial. Lancet 2002;359:1291-300.

19. Segnan N, Senore C, Andreoni B, et al. Baseline findings of the Italian multicenter randomized controlled trial of "once-only sigmoidoscopy”: SCORE. J Natl Cancer Inst 2002;94:1763-72.

20. Weissfeld JL, Schoen RE, Pinsky PF, et al. Flexible sigmoidoscopy in the PLCO cancer screening trial: Results from the baseline screening examination of a randomized trial. J Natl Cancer Inst 2005;97:989-97. 


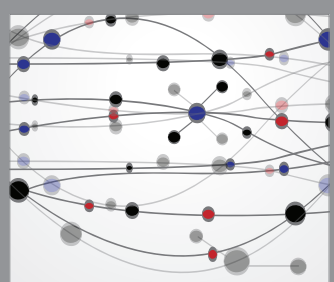

The Scientific World Journal
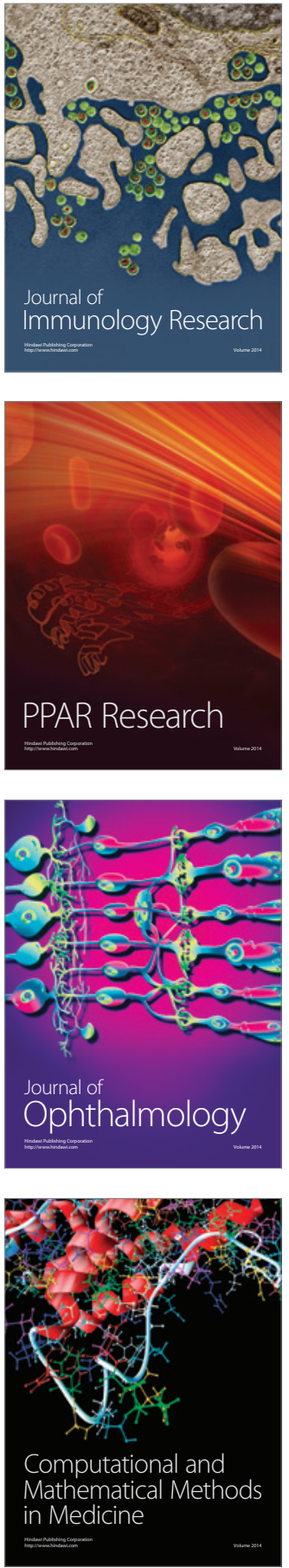

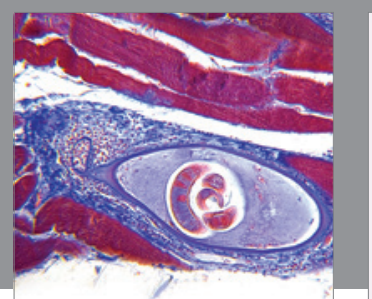

Gastroenterology Research and Practice

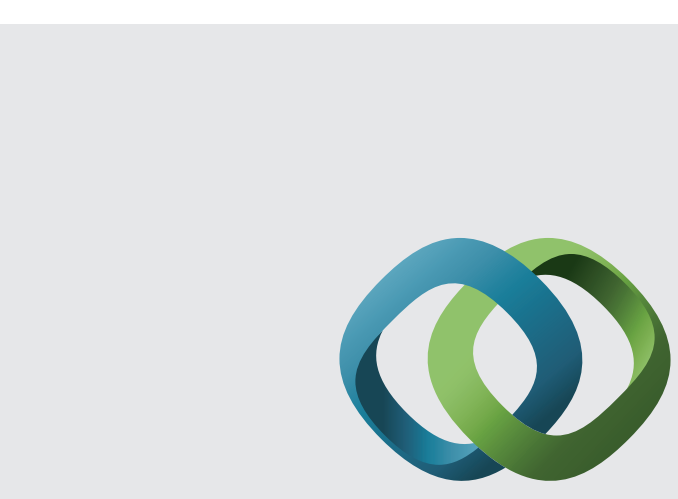

\section{Hindawi}

Submit your manuscripts at

http://www.hindawi.com
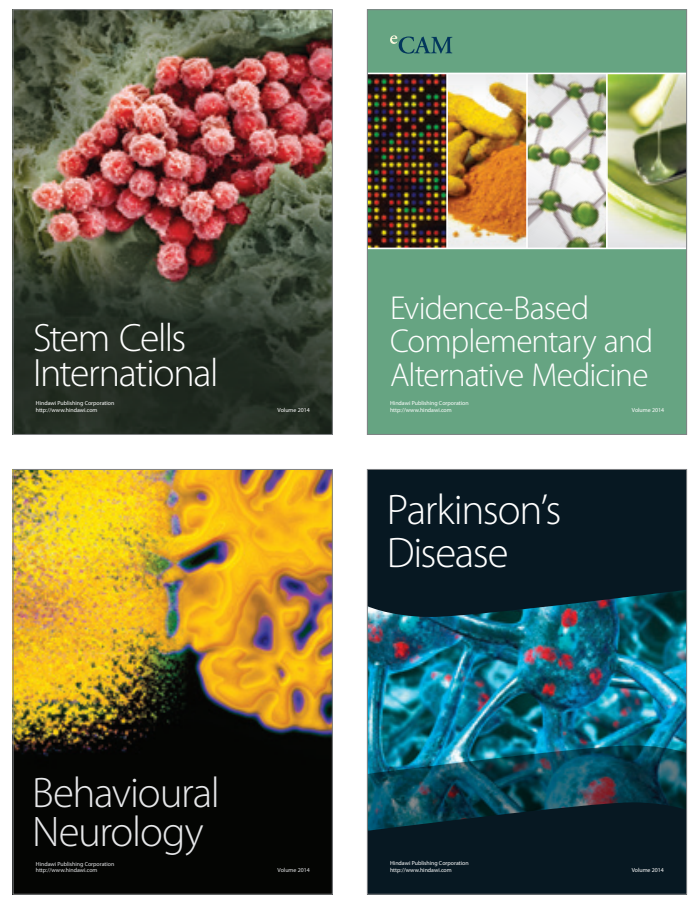
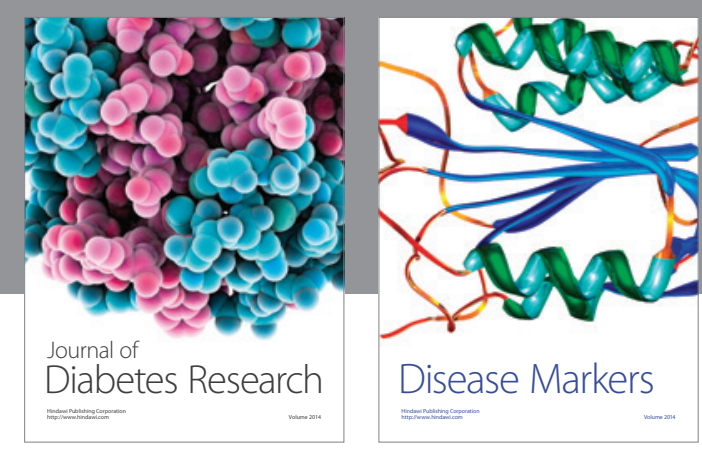

Disease Markers
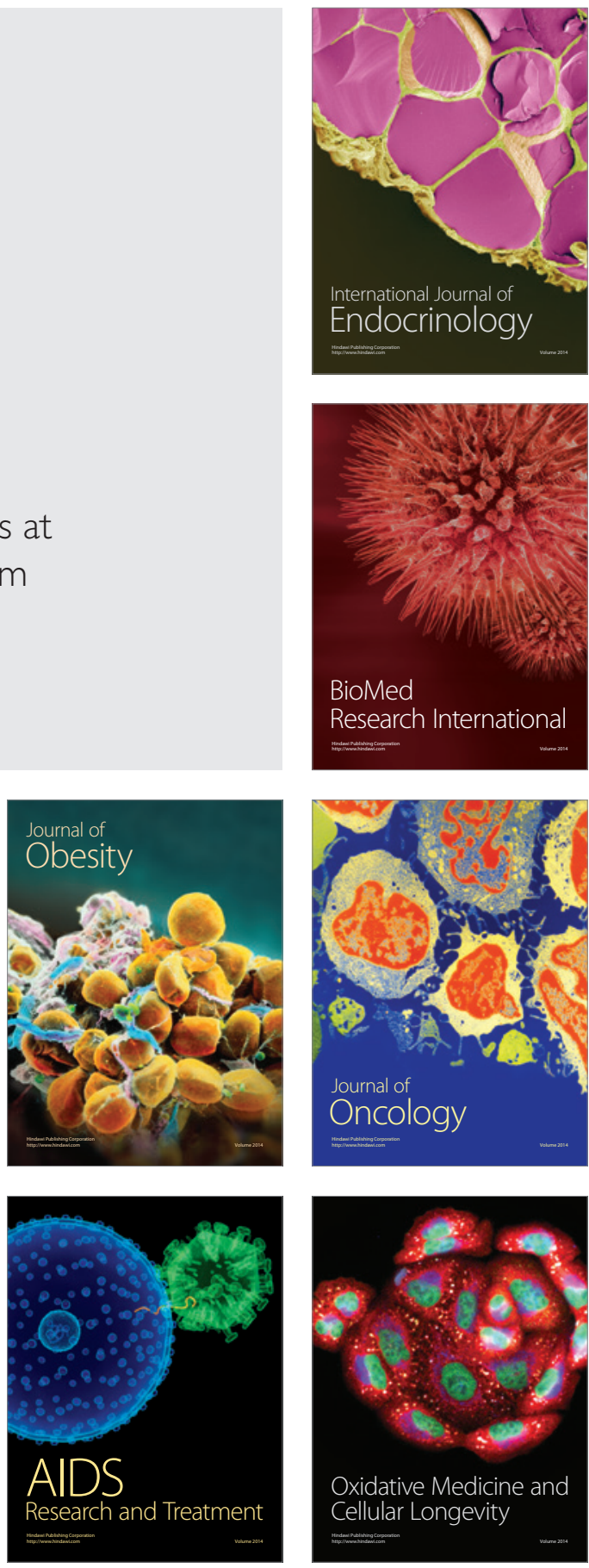